\title{
Risk Analysis of Tunnel Construction Scheme Change based on Field Monitoring and Numerical Analysis
}

\author{
Zhanping Song $\mathbb{C D}^{1,2}$ Wanying Su $\mathbb{D}^{1,2}$ Xiaoxu Tian $\mathbb{D}^{1,},{ }^{1,2}$ Yuwei Zhang $\mathbb{D}^{1,2}$ \\ and Guannan $\mathrm{Zhou}^{3}$ \\ ${ }^{1}$ School of Civil Engineering, Xi'an University of Architecture and Technology, Xi'an 710055, China \\ ${ }^{2}$ Shaanxi Key Laboratory of Geotechnical and Underground Space Engineering, Xi'an 710055, China \\ ${ }^{3}$ China Railway Construction Bridge Engineering Bureau Group Co., Ltd., Tianjin 300300, China
}

Correspondence should be addressed to Zhanping Song; songzhpyt@xauat.edu.cn and Yuwei Zhang; zhangyuwei@xauat.edu.cn

Received 30 September 2020; Revised 24 January 2021; Accepted 16 February 2021; Published 27 February 2021

Academic Editor: Junping Ren

Copyright ( $\odot 2021$ Zhanping Song et al. This is an open access article distributed under the Creative Commons Attribution License, which permits unrestricted use, distribution, and reproduction in any medium, provided the original work is properly cited.

Because of the surrounding environment restriction, some sections of the Lanzhou Metro Line 2 were forced to change the original open excavation method to the concealed excavation method. Among them, the ingate is the transitional section connecting the shaft and the cross passage, which is accompanied by the force conversion of the structure during the plan change process, and accidents are prone to occur. Combining this project situation, a construction scheme for turning the shaft from the cross passage into the ingate of mine line was proposed, and the finite element software is used to simulate the scheme. Numerical analysis shows that the stability of the tunnel supporting structure, shaft, and cross passage all meet the design requirements. The final ground settlement caused by the proposed construction method is $7.1 \mathrm{~mm}$, and the settlement of the vault is $11.97 \mathrm{~mm}$. It also turns out that the proposed construction method causes less deformation, and the method can be applied to the construction of the ingate conversion. The rationality of the method and numerical model was further verified by the comparison between the monitored data of surface settlement and vault sinking and numerical simulation results. Finally, the modified concealed excavation method and the original open excavation construction method is compared. It is concluded that the concealed excavation method is superior to the original open excavation method in terms of construction schedule, construction safety, economic benefits, and impact of construction on the surrounding environment. It indicates that it is a good choice to replace the construction method early if necessary. The successful implementation of this project can provide a reference for the design and implementation of similar urban subway projects.

\section{Introduction}

In recent years, subway construction has developed rapidly. Nowadays, the common methods in urban subway construction include open excavation, cover excavation [1-3], and concealed excavation $[4,5]$. Among them, the concealed excavation method includes drilling and blasting method, shield method, TBM, and pipe jacking method. The selection of construction method usually takes into account the construction conditions, surrounding rock conditions, burial depth, construction period, and surrounding environmental conditions. Open excavation is a relatively common subway station construction method. However, open excavation covers a large area and has a great impact on the surrounding environment or road traffic during construction. When the foundation pit is deep, measures should be taken to prevent foundation pit deformation and surrounding ground settlement $[3,6,7]$. Therefore, when the open excavation method is limited or the construction conditions are not allowed, the open excavation is often changed to the concealed excavation to ensure the construction period. In underground tunnel construction, the ingate is used as the transition section between shaft and cross passage. In the process of construction, with the stress conversion of the structure, there are many times of surrounding rock disturbance, and the amount of settlement increases, which is easy to cause accidents; it is the key and difficult point of concealed excavation construction. 
Therefore, it is very important to make a reasonable construction scheme and reasonable planning of the construction step [8-11].

In response to the problem of open excavation method and concealed excavation method scheme changes, Wei et al. [12] briefly described a station of Guangzhou Metro Line 5 , which changed the original open excavation method to the concealed excavation method to avoid the existing building. Jiang [13] proposed to change the open excavation to the concealed excavation according to the characteristics of the interlaced section of a tunnel in Changsha, such as small interval, poor geological conditions, and surrounding environment interference. Due to the inconvenience of pipeline relocation during the construction of No. 3 and No. 4 entrances and exits of a pedestrian tunnel in Shenzhen, Jiang [14] optimized the construction method and changed it to a more economical concealed excavation construction. Zhao [15] proposed to choose open excavation and concealed excavation according to the actual situation and gathering in buildings; close to roads and other places, the construction of dark excavation is beneficial. In view of the stability problems of the ingate of the subway tunnel, Yao [16] analyzed the construction method of the ingate under different construction conditions. Jiang [17] took the ingate of a certain shaft of Shenzhen Metro Line 5 as an engineering example and found that, when the pipe shed and advance small pipe are used, the settlement of the ground and surrounding structures can be effectively controlled. Xin [18] used FLAC3D numerical software to conduct a nonlinear dynamic analysis of the stability of ingate's surrounding rock and obtained the distribution law of the stress field and plastic zone of ingate under dynamic load and the mechanism of impact failure. Wei et al. [19] used FLAC 3D software to numerically simulate the construction process of ingate and pointed out that, under deep burial conditions, the uplift of the surrounding rock of the ingate floor is relatively large, and it is necessary to take targeted measures.

According to the above literature review, there are many studies on the stability of ingate. Research on the structural stress and deformation of ingate in large cross section tunnel with shaft and cross passage is relatively rare. Studies on the stability of shaft and cross passage in scheme change are also rarely reported. In this paper, the construction of the tunnel shaft and the cross passage turning into the mine line in the parking lot of Paihong south road of Lanzhou Metro Line 2 is taken as the project background. This paper introduces in detail the construction optimization scheme that an open excavation section is forced to change to a concealed excavation for some reasons. Numerical simulation and field monitoring were used to analyze the stability of the modified construction scheme. It can provide reference for the design and construction of shaft and cross passage turning into the mine line in subway tunnel engineering.

\section{Engineering Background}

2.1. Project Overview. The Paihong South Road parking lot of Lanzhou Metro Line 2 is located in Chengguan district of Lanzhou city. The underground section of the access line section is connected with bus No. 5 company station in the west and the parking lot of Paihong Road in the east. The total length of the section tunnel is $765.7 \mathrm{~m}$, of which, the open cut section length is $490 \mathrm{~m}$, design mileage: $\mathrm{K} 0+300.00 \sim \mathrm{K} 0+790.00$, the concealed excavation section length is $275.7 \mathrm{~m}$, design mileage: $\mathrm{K} 0+024.30 \sim \mathrm{K} 0+300.00$, and the plan layout drawing is shown in Figure 1. In the actual construction, the original design $\mathrm{K} 0+300.00 \sim+382.00$ open excavation section was changed from open excavation construction to concealed excavation construction due to the limitation of construction environment and existing shaft. In this paper, according to the characteristics of this project change, the scheme is described in detail.

The access line is located in the valley basin on the south bank of the Yellow River. The landform type belongs to the eroded accumulation valley plain, and the site landform unit belongs to the Yellow River Class II terrace. Above the entrance and exit lines are mainly the existing roads, green belts, and crosswalks. The terrain of the site is high in the east and low in the west, and the ground elevation of the exploration site is $1524.84 \sim 1535.22 \mathrm{~m}$. The site stratum is mainly composed of quaternary artificial fill $\left(Q_{4}{ }^{\mathrm{ml}}\right)$, quaternary Holocene alluvial loess soil $\left(Q_{4}{ }^{a l}\right)$, sand pebbles, and lower tertiary Oligocene $\left(E_{3}\right)$ siltstone. The geological longitudinal section is shown in Figure 2. The distribution types of groundwater level, aquifer, and water-barrier layer are diving. The buried depth of groundwater level is $11.2 \sim$ $22.9 \mathrm{~m}$, and the elevation of water level is $1512.32 \sim$ $1515.16 \mathrm{~m}$. The aquifer is mainly pebble layer, and the thickness of the aquifer is about $2.9 \sim 11.0 \mathrm{~m}$.

\subsection{Disadvantages of Using Open Excavation Construction Method}

(1) The original open cut section of $\mathrm{K} 0+300 \sim+382$ has a large flow of people in the construction street, and the long-term occupation of the street in the construction process will bring great social impact. The overhead communication line and the access line of the north side road of the open excavation traffic are low, and the higher truck will hang up the access line Figures 3(b) and 3(c).

(2) There is a power pole at the road leading to the main road, and the vehicle cannot pass through. The site replacement costs are high and take a long time, and there is no site to replace. Due to the impact of migration and weak electricity relocation, the road cannot be released, the excavation site enclosure does not have the conditions, and the open excavation section cannot be started, resulting in uncontrollable construction duration Figure 3(a).

(3) The construction site is small, which causes the problems of inconvenient construction organization and low efficiency.

(4) The open excavation section is occupied by the shaft site, and the cost of using the open excavation method is greater. Meanwhile, the completion time 


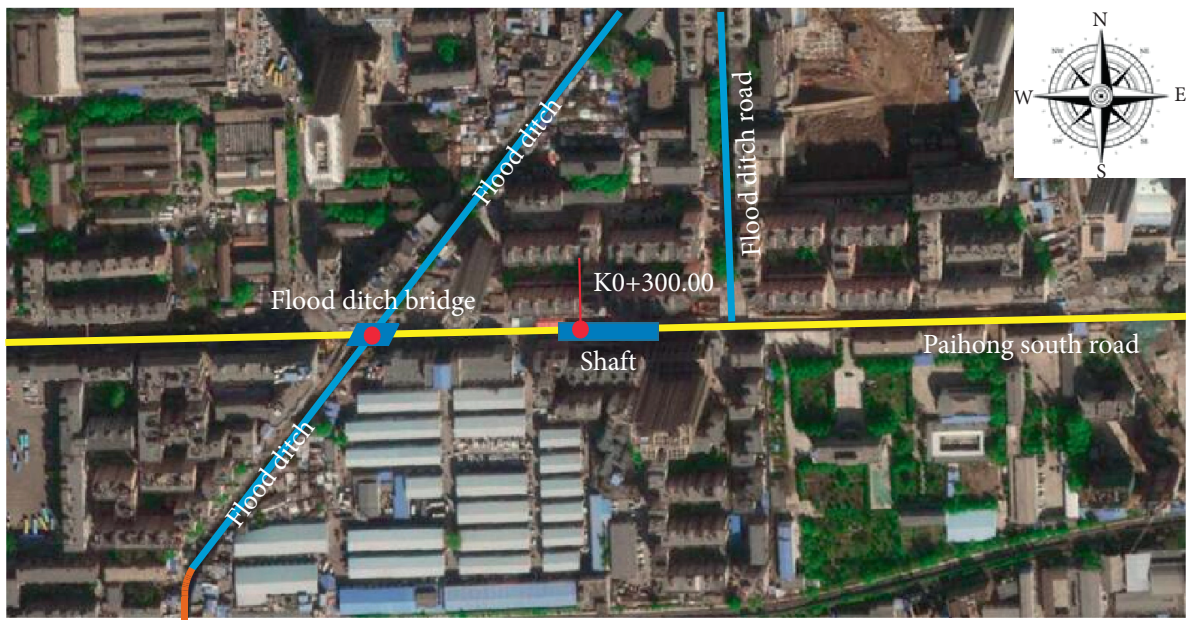

FIGURE 1: Schematic layout of entry-exit line marking section.

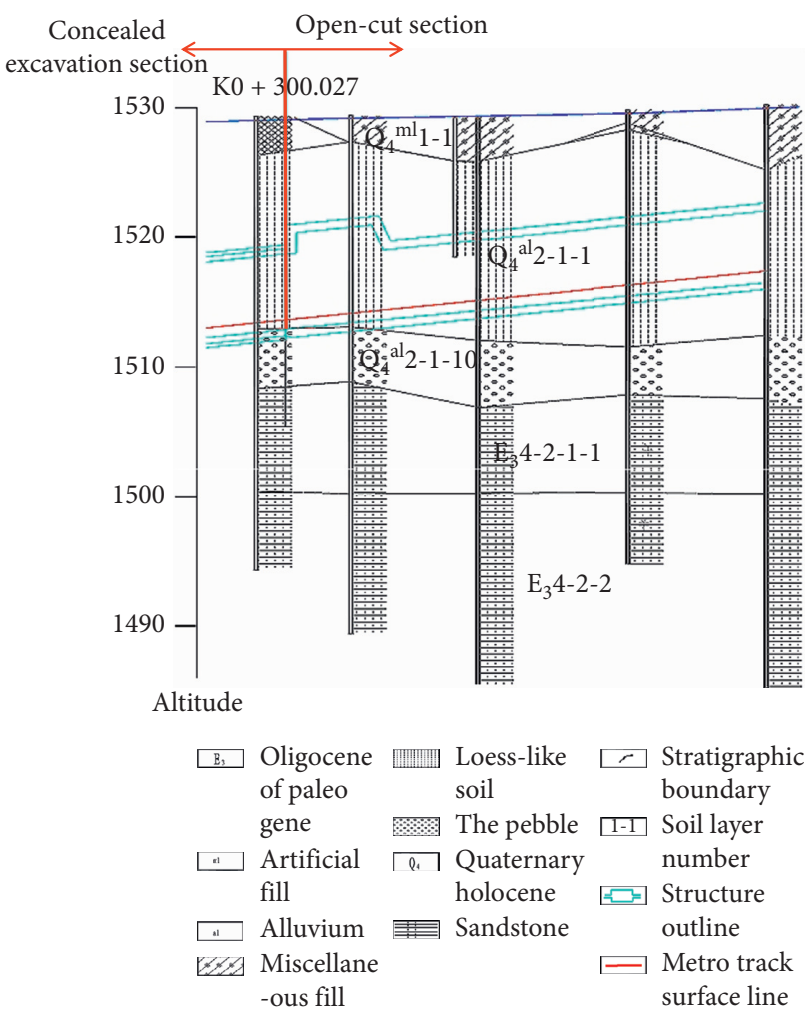

FIgURE 2: Geological profile.

of the concealed excavation section will be until the completion of the project, and the open excavation section will not be able to be excavated within this time.

(5) The section of $\mathrm{K} 0+300 \sim+382$ is the deepest section of open excavation, and deep foundation pit will bring greater construction risk. The enclosure area of the site is small. Besides the area occupied by the foundation pit, there are also the placement of personnel, construction materials, and construction machinery. The access of personnel and materials will cause greater safety risks to the construction personnel. In summary, the open excavation method has many constraints, and the construction is difficult, resulting in uncontrollable construction time and increased costs. The plan was optimized and the $\mathrm{K} 0+300 \sim+382$ open excavation section was changed to the concealed excavation method. The second section introduces the construction scheme after the change in detail.

\subsubsection{Optimization Plan for Construction by Changing Open} Excavation Method to Concealed Excavation Method. As the transition section between shaft and cross passage, ingate is the throat of the subway shaft. During the construction process, with the structural stress conversion, the surrounding rock has many times of disturbance, the settlement is large, and it is easy to have accidents. It is a key issue in the process of tunnel construction by concealed excavation. Therefore, it is very important to formulate a reasonable ingate construction plan and plan the construction steps reasonably. In view of the change from open excavation to concealed excavation in the entrance and exit line tunnel of the parking lot of Paihong South Road, there are four opening faces in the tunnel when the construction cross passage is transferred into the section tunnel. Its complex and frequent stress conversion has a great impact on the deformation and stability of the tunnel and the surrounding buildings. Therefore, it is necessary to study the construction technology in order to reduce the safety risk in the construction process and ensure the project quality.

2.3. Construction Scheme of Shaft into Cross Passage. The construction of the shaft into the cross passage adopts the method of excavating the cross passage after permanently sealing the bottom of the shaft.

The specific construction steps are as follows: (1) construction of the lock section: after manual excavation of the lock to the design depth, the excavation shaft wall and frame formwork shall be closed in time for concrete pouring; (2) shaft construction: determine the initial support of the shaft 


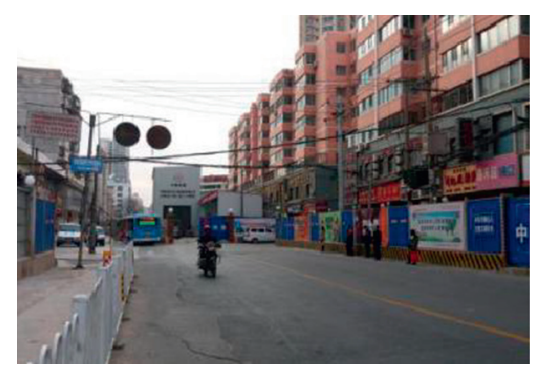

(a)

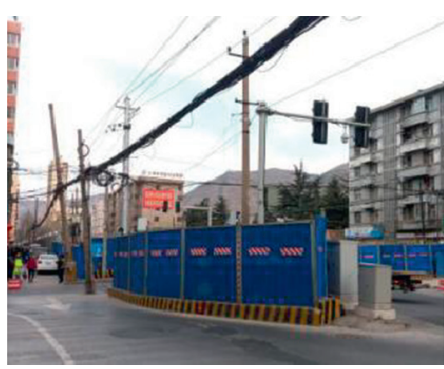

(b)

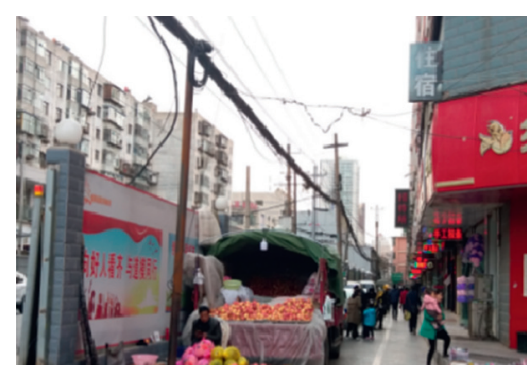

(c)

Figure 3: Power line status in construction section. (a) Communication lines. (b) Overhead status of communication lines. (c) Household line.

wall according to the actual engineering geology; (3) construction of the shaft bottom; (4) construction of ingate after breaking the cross passage support: after the completion of the construction at the bottom of the shaft, the ingate shall be reinforced. According to the design, advance grouting small conduit shall be set and grouted. After the slurry is solidified, the concrete on the steps of the ingate shall be removed, the steel grid shall be erected, and the excavation surface shall be closed by shotcreting; (5) when the construction step of the upper step reaches 3 times the diameter of the single center circle of the cross passage, the concrete under the step of the ingate is removed, the steel grid and shotcrete are erected, the initial support of the cross passage is completed, and the construction of the ingate is completed. Follow this cycle to complete the construction of the next cross passage.

\subsection{Construction Scheme of Shaft and Cross Passage into Main} Tunnel. The construction process of the double-section arch adopts the middle guide hole and step method for excavation. In order to exert the three-dimensional support effect of the palm face, the core soil part is retained during the construction of the upper half section to maintain the stability of the palm face. The main points of construction technology are as follows:

(1) Before breaking the ingate of the interval tunnel, the combination of large pipe shed and advance small pipe grouting shall be used to prereinforce the stratum. The advanced pipe shed support uses a seamless steel pipe with an outer diameter of $108 \mathrm{~mm}$, a wall thickness of $8 \mathrm{~mm}$, and a single length of $24 \mathrm{~m}$. The small conduit support adopts a small grouting conduit with an outer diameter of $32 \mathrm{~mm}$ and a single length of $5 \mathrm{~m}$, with a longitudinal overlapping length of $3 \mathrm{~m}$, a circular spacing of $0.4 \mathrm{~m}$ at the arch, and a plum-shaped arrangement of $1.0 \mathrm{~m} * 1.0 \mathrm{~m}$ at the working face. When entering the tunnel, the three steel frames are arranged closely and connected with the open excavation structural reinforcement. The design diagram of the advance reinforcement is shown in Figure 4.

(2) Each step of the interval tunnel step should not be too long; $3 \sim 5 \mathrm{~m}$ is appropriate. After $20 \mathrm{~m}$ of middle drift excavation, the lining construction of mid- partition shall be started, and temporary support shall be set up to prevent the displacement of midpartition. The middle drift shall continue to be excavated and the side tunnel construction shall be started at the same time.

(3) Because the cross passage is inclined to the west, the steel frame of the middle drift in the shaft cannot be formed into a ring when the middle drift is constructed in the east side of the cross passage. The steel frame in the middle of the supporting tunnel is used to reinforce the south side so that the north hole can form a ring normally. The location of reinforcement measures is shown in Figure 5.

The specific construction steps are as follows:

(1) Excavation of middle drift (upper): implement advance support at the entrance, remove the support of shaft and cross passage in the upper bench of the middle drift, carry out the small pipe grouting in advance of the middle drift arch top, and then excavate the upper bench of the middle drift to retain the core soil and carry out the initial support and temporary invert for the upper bench (Figure 6(a)).

(2) Excavation of middle drift (lower): remove the support of shaft and cross passage within the scope of lower steps of the middle drift, excavate the lower steps of the middle drift, and construct the initial support (Figure 6(b)).

(3) After $20 \mathrm{~m}$ of middle drift construction, the middle partition wall construction shall be carried out. Meanwhile, carry out the lining construction and set up the temporary support to prevent its displacement (Figure 6(c)).

(4) Excavation of side drift (upper): Remove the shaft and cross passage support within the step range of the side tunnel, carry out the small pipe grouting ahead of the arch top of the side tunnel, and then excavate the step staggered distance of the left- and right-side tunnels for $5 \mathrm{~m}$; then carry out the initial support (3 steel frames are arranged side by side in ingate section to improve the safety reserve of the weak section) and the temporary inverted arch support (Figure 6(d)). 

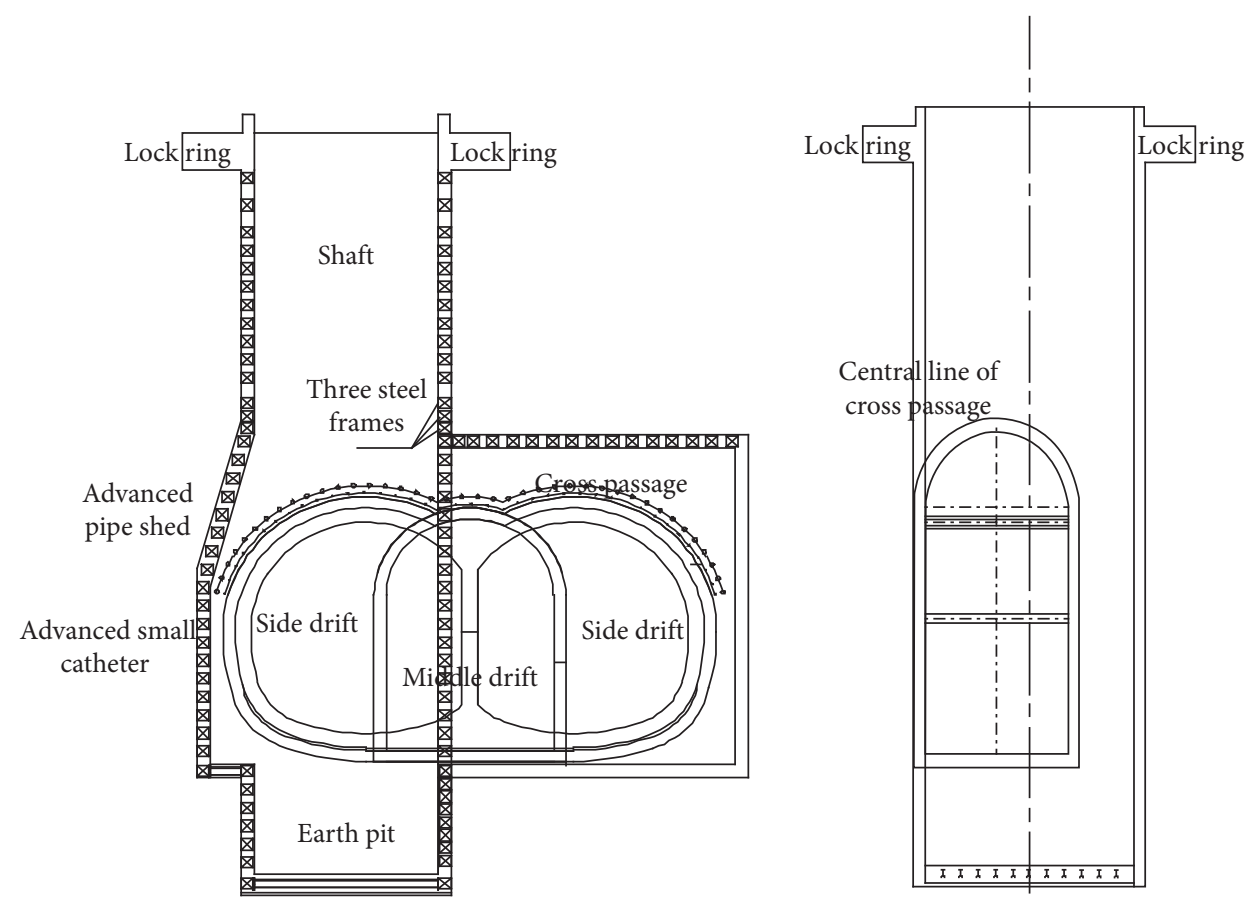

FIGURE 4: Section of ingate.

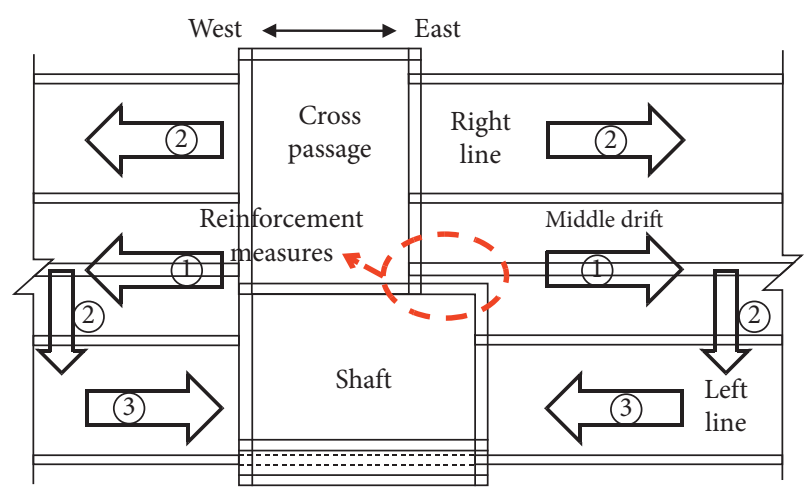

FIGURE 5: Opening ingate from shaft to east and standard section.

(5) Excavation of side drift (lower): Remove the support of shaft and cross passage within the scope of lower steps of side tunnel, excavate the lower steps of side tunnel, and construct the initial support and inverted arch (Figure 6(e)).

(6) Construction of side drift waterproof layer and secondary lining: After the tunnel convergence has stabilized, construct a second reinforced concrete lining and remove the temporary support in the tunnel (Figure 6(f)).

The construction steps of the underground excavation tunnel are shown in Figure 6.

The mileage of open and concealed excavation junction changes from $\mathrm{K} 0+300$ to $\mathrm{K} 0+382$. Before the excavation of the middle pilot tunnel to $\mathrm{K} 0+382$, the open excavation of retaining pile here shall be completed. If the lateral enclosure pile at the open excavation end is not completed, the construction of the concealed excavation shall be stopped
$5 \mathrm{~m}$ away from the enclosure pile, and the tunnel face shall be temporarily closed. When the main structure of the connection section of open excavation is completed, the pile shall be broken at the open excavation side.

\section{Numerical Simulation of Shaft and Cross Passage into the Ingate Construction}

In order to determine the stability of the structure after the change of the open excavation section to the concealed excavation section of the $3 \mathrm{~A}$ parking lot of Lanzhou Rail Transit Line 2 and to predict the possible safety problems in the construction, Midas GTS software was used for numerical simulation $[20,21]$.

\subsection{Establishment of Calculation Model. Using Midas GTS/} NX software, the finite element method was used to establish a three-dimensional numerical analysis model for the $\mathrm{K} 0+300 \sim 382$ concealed excavation section.

According to the related principles of rock mechanics and elastic mechanics, the affected area during construction is generally 3 times the size of the construction section $[22,23]$. According to the actual geological conditions of the project, the size of the finite element model is calculated horizontally and the width is about $90 \mathrm{~m}$ ( 3 times the tunnel span). The calculated depth from the bottom of the tunnel to the lower boundary in the vertical direction is about $48 \mathrm{~m}$ ( 3 times the hole diameter). In actual engineering, the bias voltage appears at the location of ingate and the burial depth of the tunnel gradually becomes shallower toward the east, so the entrance length of ingate along the longitudinal direction of the tunnel is $30 \mathrm{~m}$ as the calculated length of the model. The lateral and bottom sides of the model adopt displacement boundary 


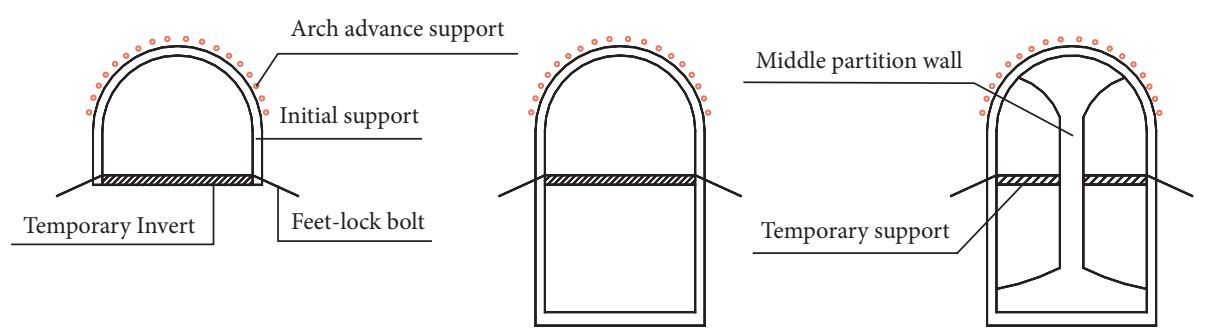

(a)

(b)

(c)

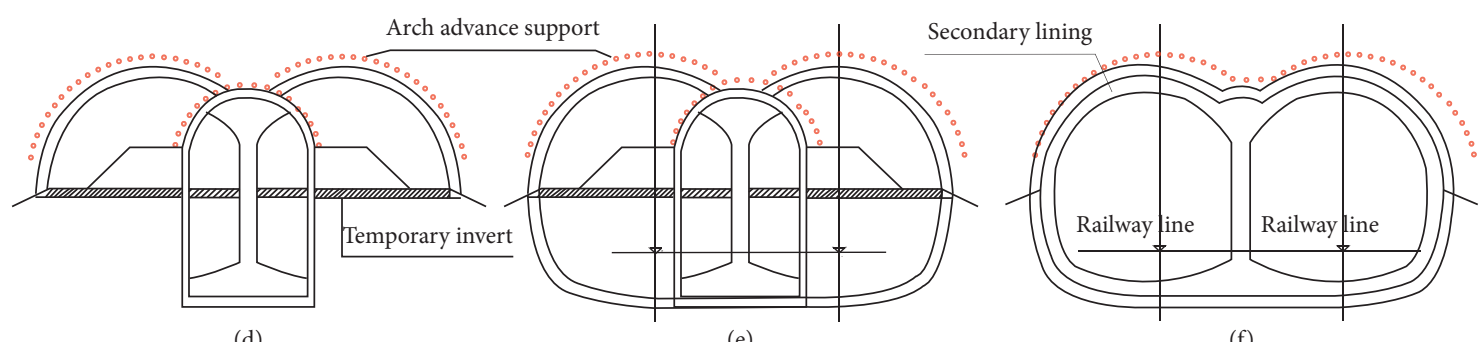

(d)

(e)

(f)

Figure 6: Construction steps of concealed excavation. (a) Excavation of middle drift (upper). (b) Excavation of middle drift (lower). (c) Construction of middle partition wall. (d) Excavation of side drift (upper). (e) Excavation of side drift (lower). (f) Construction of side drift waterproof layer and secondary lining.

conditions and the upper surface is a free boundary. The four lateral sides along the $x$ - and $z$-axes constrain the horizontal displacement of the model. The bottom boundary constrains the vertical displacement of the model. The initial stress field is calculated according to the self-weight stress field. The construction interval is basically within the envelope structure, and the driving load on the ground is not considered; that is, the effect of variable load is not considered $[8,24]$. In order to ensure the calculation accuracy, fine elements are used around the tunnel. The model is divided into 87648 elements. The mesh of the finite element model is shown in Figure 7.

According to the "Code for Geotechnical Engineering Investigation of Urban Rail Transit," the surrounding rock is classified as grade VI. The model assumes that the rock mass is an ideal elastoplastic medium, which complies with the Mohr-Coulomb strength yield criterion. The plate element is used for the initial lining and the second liner, and the beam element is used for the pipe shed support. The advanced small pipe adopts the implantable truss unit. According to the empirical value of the project, the elastic modulus of the surrounding rock is appropriately reduced, and its cohesive force and friction angle are also appropriately reduced. According to the geological survey data obtained from field tests and structural design data, the physical and mechanical parameters of the surrounding rock and supporting structure can be determined. At the same time, the role of the arch frame is considered by the equivalent method; that is, the elastic modulus of the steel arch frame is converted to the shotcrete. The calculation method is as follows:

$$
E=E_{0}+\frac{S_{g} \times E_{g}}{S_{c}},
$$

where $E$ is the elastic modulus of the converted concrete; $E_{0}$ is the elastic modulus of the original concrete; $S_{g}$ is the crosssectional area of the steel arch; $E_{g}$ is the elastic modulus of the steel arch; and $S_{c}$ is the cross-sectional area of the concrete. The material parameters of the model are shown in Table 1.

\subsection{Calculation Results and Analysis}

\subsubsection{Safety Analysis of Main Line Support Structure}

(1) Internal Force Analysis of Initial Lining

It can be seen from the main stress cloud image of the initial support that the maximum compressive stress of the initial support is $18.65 \mathrm{MPa}$, which appears at the bottom of the initial support arch on the left side of the middle guide tunnel. It can be seen from the specification that the compressive strength of C30 shotcrete is $30.0 \mathrm{MPa}$ (Figure 8), and the initial lined compression zone is safe. At the temporary support lap and arch foot, stress concentration occurred. Although the value is within a reasonable range, this part must be paid attention to during construction to ensure safe and smooth construction of the project.

(2) Internal Force Analysis of the Second Liner

It can be seen from the main stress cloud of the second liner that the maximum compressive stress on the second liner is $11.37 \mathrm{MPa}$ (Figure 9). Under the bending and compression state, the design value of the compressive strength of the C45 moulded concrete in bending and compression is $41.2 \mathrm{MPa}$, which is greater than the maximum pressure calculated by the second liner; the stress value meets the design requirements.

(3) Internal Force Analysis of the Mid-Partition

According to the main stress cloud of the mid-partition, the maximum compressive stress of the mid-partition is 19.01 MPa (Figure 10). According to the specifications, 


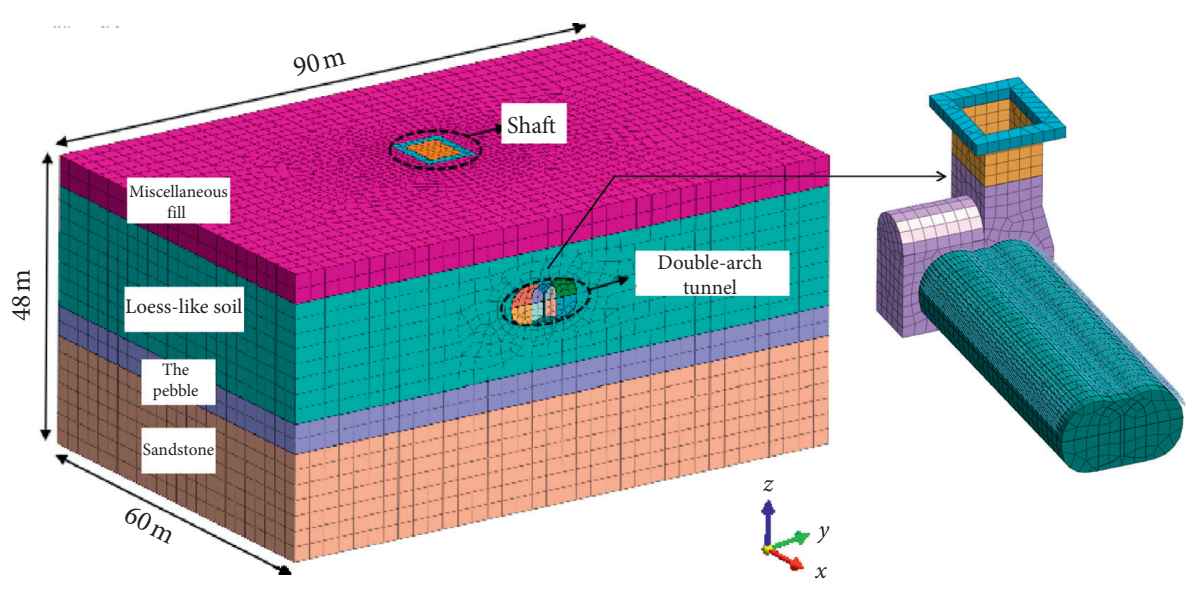

Figure 7: Calculation model.

TABle 1: Material parameters of the model.

\begin{tabular}{lccccc}
\hline Material & $E(\mathrm{MPa})$ & $\mu$ & $\begin{array}{c}\gamma \\
\left(\mathrm{kN} \cdot \mathrm{m}^{3}\right)\end{array}$ & $\begin{array}{c}C \\
(\mathrm{MPa})\end{array}$ & $\begin{array}{c}\Phi \\
\left({ }^{\circ}\right)\end{array}$ \\
\hline Miscellaneous fill & 15 & 0.39 & 15.7 & 0.01 & 12 \\
Loess-like soil & 29 & 0.30 & 17.8 & 0.017 & 21 \\
The pebble & 250 & 0.22 & 21 & 0 & 20 \\
Sandstone & 57.5 & 0.24 & 21.2 & 0.03 & 25 \\
Advance catheter & $20 \times 10^{4}$ & 0.25 & 78.5 & 0.2 & 25 \\
Big pipe shed & $18 \times 10^{4}$ & 0.25 & 78.5 & - & - \\
Concrete primary & $1 \times 10^{4}$ & 0.25 & 25 & - & - \\
support & $3 \times 10^{4}$ & 0.20 & 25 & - & - \\
Secondary lining & & & & &
\end{tabular}

the compressive strength of the corresponding C45 cast concrete is $41.2 \mathrm{MPa}$, which is lower than the compressive strength of concrete. Although the ultimate compressive strength requirements of the section steel are met, the concrete may be damaged by compression, so the spacing between the palm surfaces of the upper and lower steps must be strictly controlled, the initial support should be applied in time, and the area should be monitored.

3.2.2. Stability and Deformation Displacement Analysis of Shaft and Cross Passage. After the construction of the ingate on the west side of the shaft is completed, the open excavation scheme of the $\mathrm{K} 0+300 \sim+382$ section of the parking lot entrance and exit section of the 3A section of the Lanzhou Rail Transit Line 2 is changed to the concealed excavation scheme, which will inevitably cause the second-order perturbation (Figures 8-11). In the actual construction process, the support structure of the shaft is more sensitive to the construction excavation plan, and the secondary disturbance during construction has a greater impact on the stability of the support structure [15].

According to the stress cloud diagram of the simulation calculation results of the shaft and the cross passage, the maximum pressure of the supporting structure is $14.10 \mathrm{MPa}$, which appears at the arch top of the east ingate excavation (Figure 11). The strength of the supporting structure of the shaft is considered according to the initial strength of C30

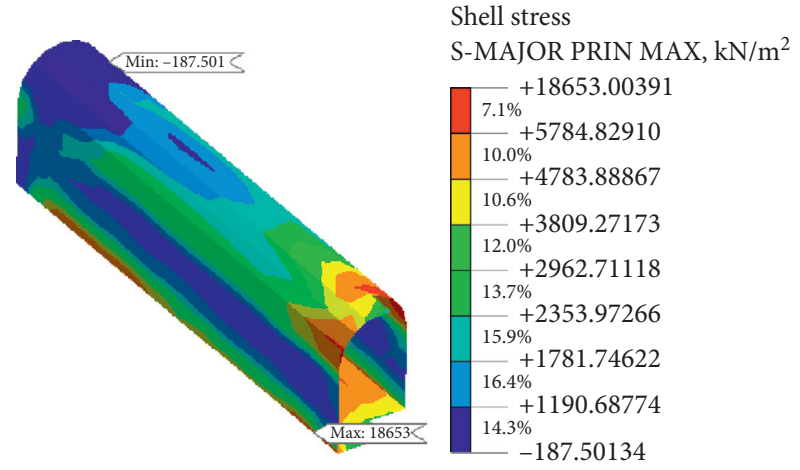

FIgURE 8: Maximum principal stress of initial support.

shotcrete, which is $30.0 \mathrm{MPa}$ lower than the compressive strength of the concrete. Furthermore, according to the numerical simulation stress cloud diagram, the area of the stress concentration area is small, and it is considered that the shaft and the horizontal channel can guarantee the safe construction of the project. However, during the construction of ingate, it is still necessary to strengthen the initial shaft structure and increase the monitoring frequency of the supporting structure.

In order to ensure that the supporting structure of the shaft and the cross passage in the construction of the east ingate will not affect the normal construction of the project due to excessive deformation, the vertical deformation cloud map of the shaft and the cross passage in each characteristic stage of the tunnel construction is given in Figure 12 according to the numerical simulation results. Vertical upwards is positive and downwards is negative. With the increase of the stress of the construction support structure of the tunnel, the settlement of the arch crown and the uplift of the arch bottom also increase. At the completion stage of construction, the maximum vertical settlement value of ingate is $6.74 \mathrm{~mm}$, which occurs at the arch top of the right tunnel, and the maximum vertical uplift is $5.72 \mathrm{~mm}$, which occurs at the arch bottom of the right tunnel.

During the construction of the main tunnel, the settlement and uplift mainly occurred in the east side of the shaft near the cross passage. It can be seen that the maximum settlement value appears at the vault of the 


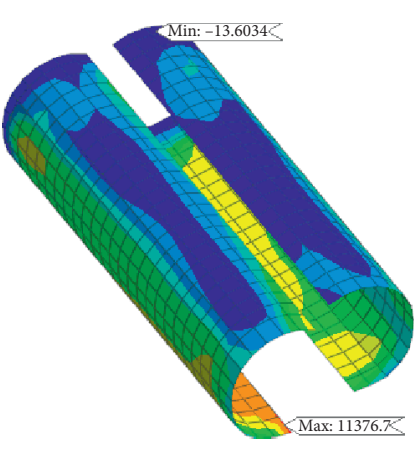

Shell stress

S-MAJOR PRIN MAX, $\mathrm{kN} / \mathrm{m}^{2}$

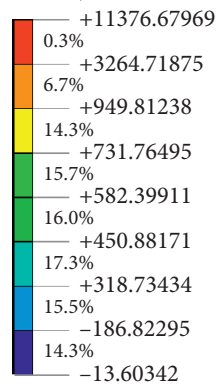

(a)

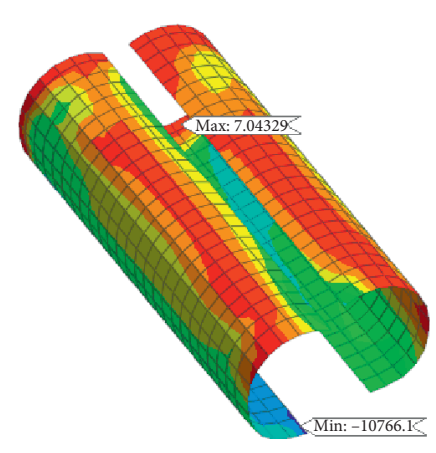

Shell stress

S-MINOR PRIN MAX, $\mathrm{kN} / \mathrm{m}^{2}$

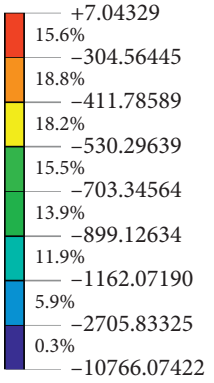

(b)

Figure 9: Maximum and minimum principal stress of the second liner.

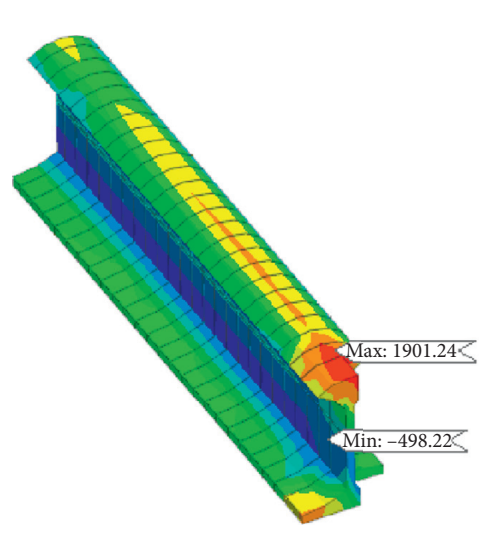

(a)
Solid stress S-PRINCIPAL A, $\mathrm{kN} / \mathrm{m}^{2}$

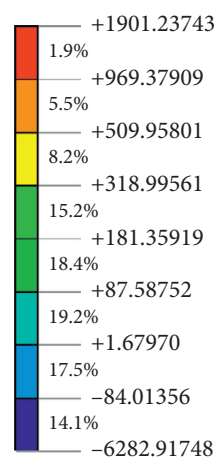

$-6282.91748$

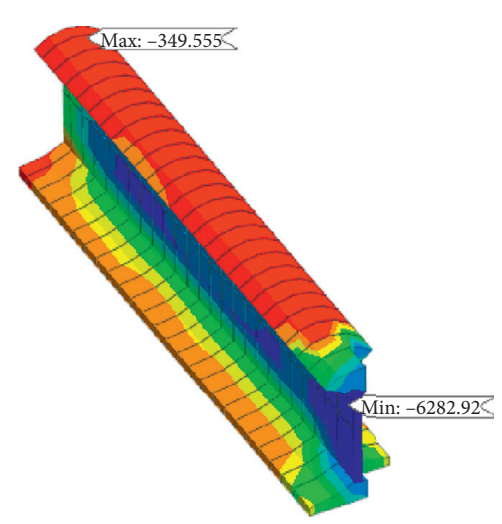

Solid stress

S-PRINCIPAL C, $\mathrm{kN} / \mathrm{m}^{2}$

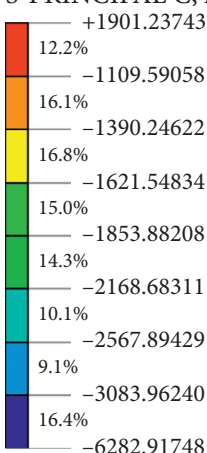

(b)

FIGURE 10: Maximum and minimum principal stress of mid-partition.

(a)

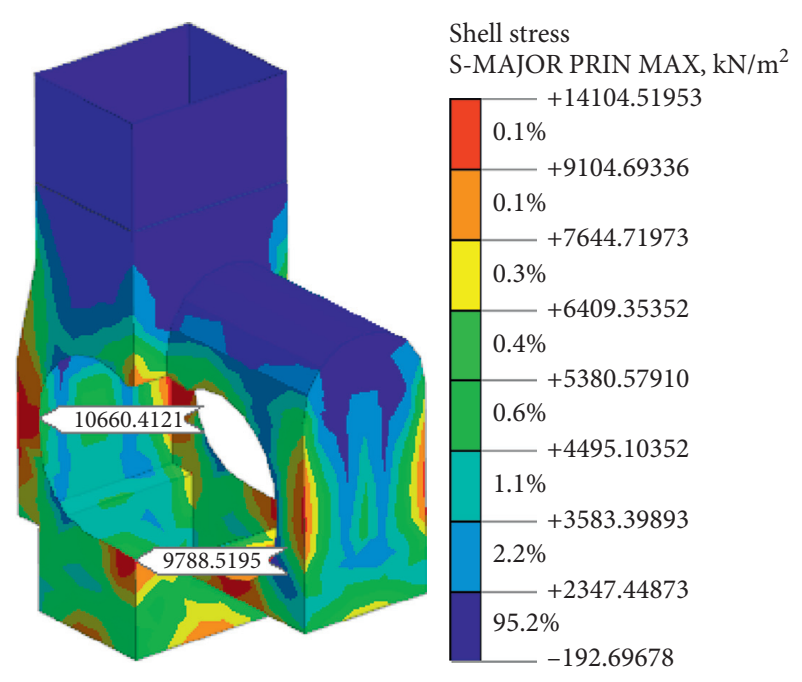

FIGURE 11: Distribution of maximum and minimum principal stress in the supporting structure of cross channel and shaft.

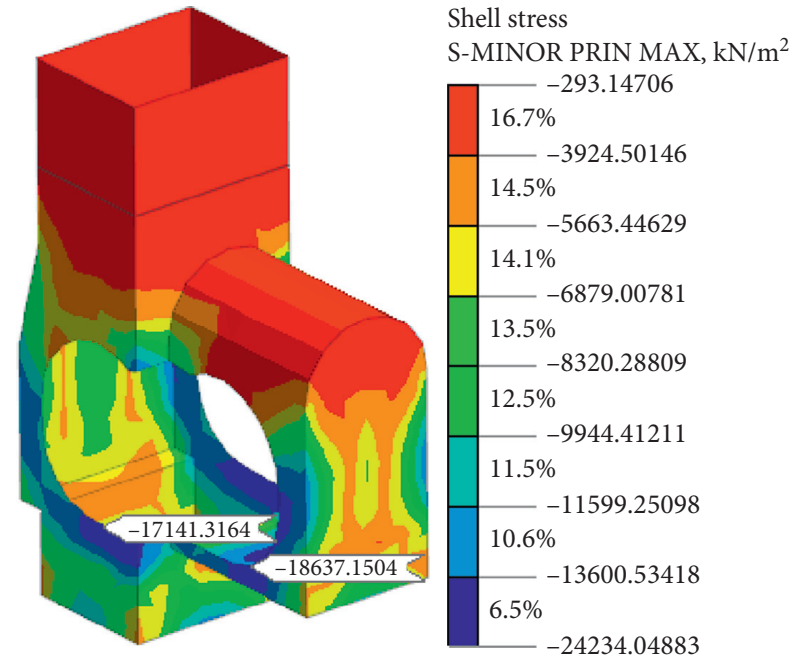

(b) cross passage about $3.5 \mathrm{~m}$ away from the shaft. It is speculated that this is the edge of the plastic zone of the shaft, resulting in the separation layer. The further away from the shaft, the smaller the settlement value. During the construction of the middle drift, the breaking support has almost no effect on the deformation of the arch 


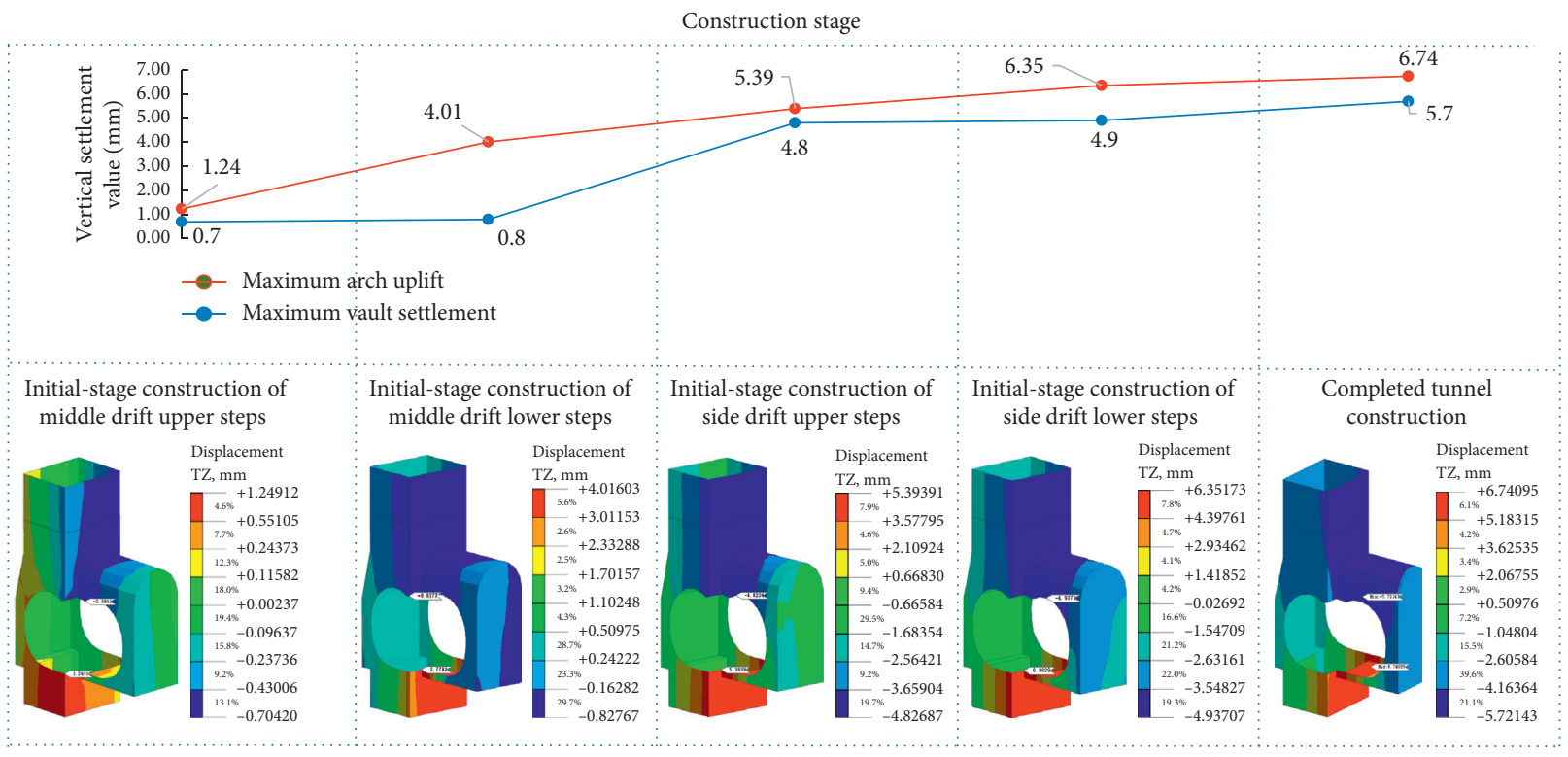

FIGURE 12: Vertical deformation cloud of supporting structure.

crown. During the step construction of the side tunnel, the settlement value of the arch crown increases abruptly during the breaking support, and its position is transferred from the arch crown of the middle drift to the arch crown of the side tunnel, which indicates that the breaking support of the side tunnel in a larger scope has no stable point of force and loses the supporting function. On the whole, with the construction, the settlement range and value are gradually increasing. Due to the measures of erecting steel frame to form a ring, the deformation of ingate on the east side is far less than the warning range when the support is broken.

Figure 13 shows the horizontal deformation cloud chart of the shaft and cross passage in each characteristic stage during the tunnel construction. The "+" value is the positive (east side) deformation of the $x$-axis, and the "-" value is the negative (west side) deformation of the $x$-axis. With the gradual increase of the stress of tunnel construction support structure, the horizontal deformation also increases. In different construction stages, the location of the maximum horizontal deformation in the direction of ingate on the east side is also different, which is directly related to the sequence of support breaking. When the support is broken in the construction range of the above steps, the maximum horizontal displacement occurs in the vault. The maximum horizontal displacement in the west direction occurs at the bottom of the arch on the east side of the left tunnel. It is speculated that it is due to the closing and looping measures of the ingate on the east side, which should be paid more attention to in the actual construction.

3.2.3. Stratum Settlement Analysis and Surrounding Rock Plastic Zone Analysis. Paihong South Road is located in the old urban area of Lanzhou city, where houses and other buildings are densely packed. In order to analyze the impact of tunnel construction on the surrounding environment after completion, the corresponding settlement data of tunnel section is extracted based on the numerical simulation results of finite element method. The ingate is the site of major concern after the scheme is changed. Therefore, the section $\mathrm{K} 0+305$ above the east horse's head gate is selected to analyze the law of surface settlement at each stage. The surface settlement curve at each stage is shown in Figure 14. There is no change in the ground settlement during the excavation of the middle drift. The maximum value of surface settlement occurs at $10 \mathrm{~m}$ from the left side of the tunnel centerline, and the settlement value gradually decreases from $10 \mathrm{~m}$ from the left side of the tunnel centerline to both sides. The settlement value is reduced from 0 to $10 \mathrm{~m}$ to the right of the tunnel centerline. The reason is that it is located in the shaft lock ring, which plays a certain role in strengthening the stratum settlement. The final settlement value of the tunnel is about $7 \mathrm{~mm}$, which is smaller than the warning value of ground settlement in the large section construction, meeting the construction control requirements [16].

After the completion of the excavation of the middle drift, the plastic zone of surrounding rock mainly appears at the side wall and arch waist positions on both sides of the middle drift, and the maximum plastic strain appears at the arch foot position on the left side of the middle drift. After the construction of the upper steps of the side hole is completed, the plastic zone of surrounding rock mainly appears below the arch waist of the side hole, and the maximum plastic strain still appears at the arch foot position on the left side of the middle drift (Figure 15). Necessary measures should be taken during the construction. In order to avoid the erosion of the rock on the face of the arch and the erosion of the rock at the foot of the arch, it is necessary to seal shotcrete in time, establish the initial support structure in time, and even advance grouting (Figure 15). 


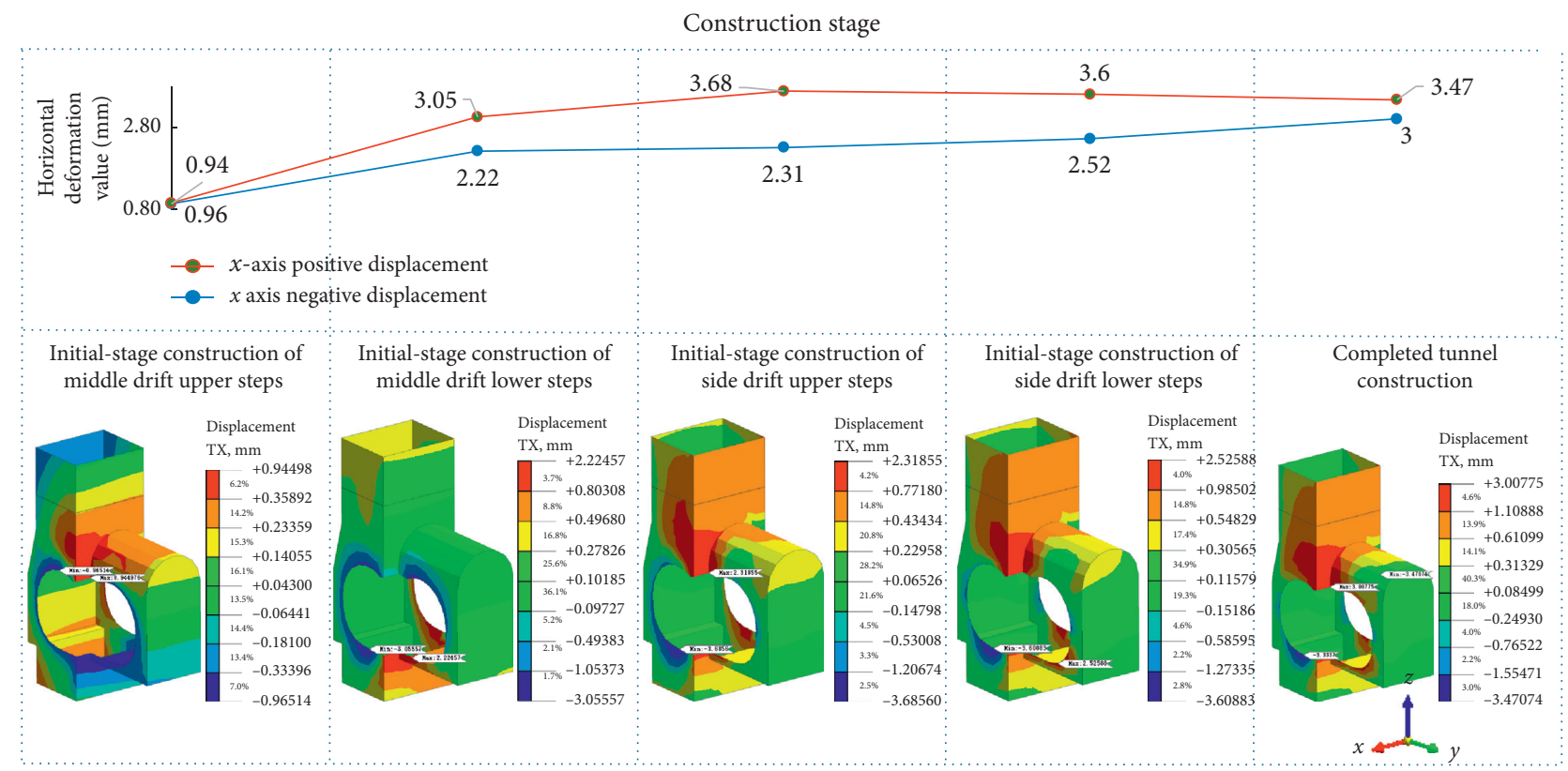

FIGURE 13: Horizontal deformation cloud of supporting structure.

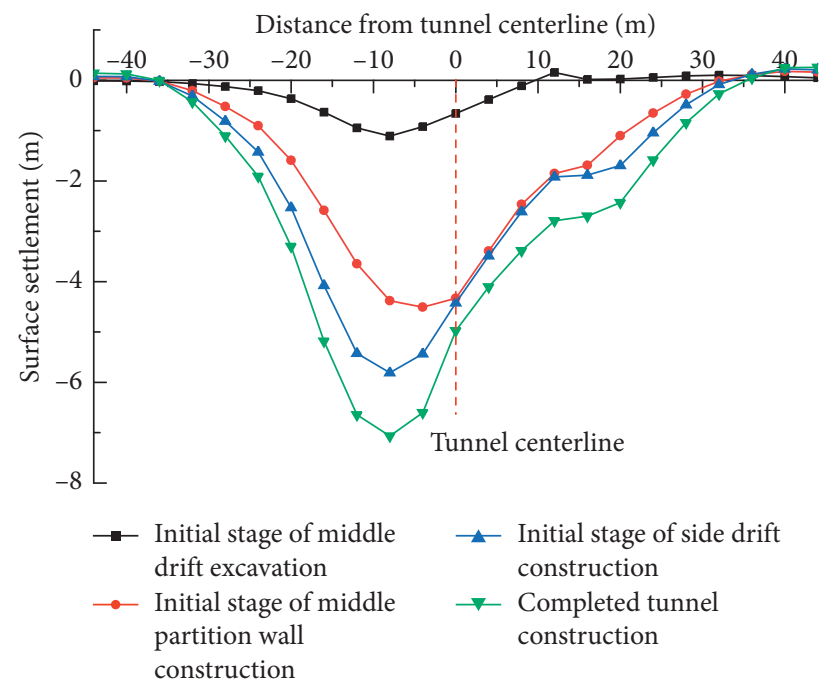

Figure 14: Surface settlement curve.

3.2.4. Analysis of Vault Settlement. The characteristic section $\mathrm{RK} 0+300$ of shaft and cross passage is selected for analysis of vault settlement, and the curve of vault settlement is shown in Figure 16. When the upper step of the middle drift breaks the wall, the monitoring point will produce vertical displacement. During the upper step construction, the settlement change of the middle drift vault is $7.4 \mathrm{~mm}$, accounting for 3/5 of the total settlement of the middle guide tunnel vault, which shows that the removal of the shaft and cross passage support has a great impact on the vault settlement. In the actual construction, the vault support should be carried out in time. During the wall breaking construction of the lower steps of the middle drift, the settlement trend of the vault is gentle and gradually stable, and the final settlement is $11.97 \mathrm{~mm}$. The construction of the left and right tunnels has little impact on the settlement of the middle drift vault. The sudden increase of the vault settlement of the leftand right-side tunnels occurs after the wall breaking in the upper step of the left and right tunnels. After the vault support, the settlement tends to be gentle, the final settlement of the left tunnel is $13.94 \mathrm{~mm}$, the final settlement of the right tunnel is $15.44 \mathrm{~mm}$, and the vault settlement of the right tunnel is slightly larger than the left tunnel. According to the above analysis, it can be concluded that the main influencing factor of the vault settlement in this construction section is the support breaking in the scope of the cross passage and shaft, so it is very important to carry out the support in time after the wall breaking.

Figure 17 shows the vault settlement curve of $\mathrm{RK} 0+310, \mathrm{RK} 0+320$, and $\mathrm{RK} 0+330$ sections. It can be 


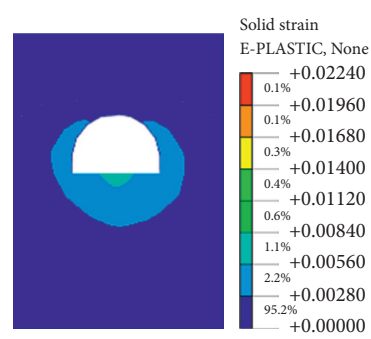

(a)

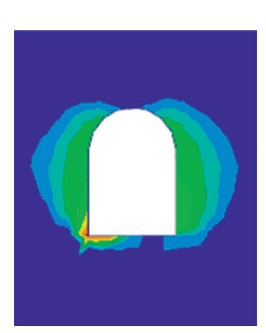

(b)

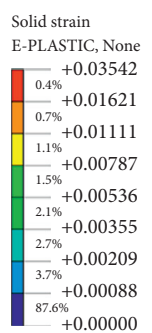

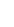

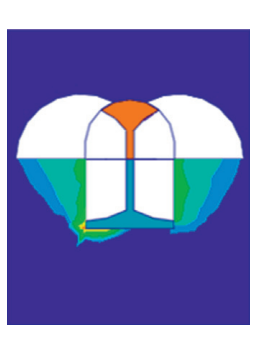

(c)

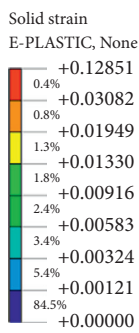

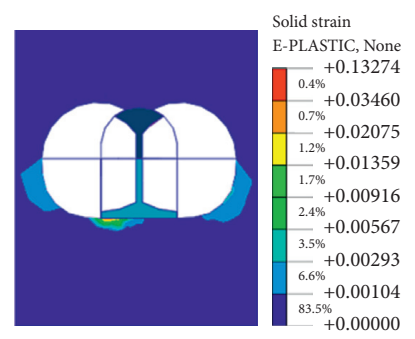

(d)

FIGURE 15: Distribution of plastic zone insurrounding rock.

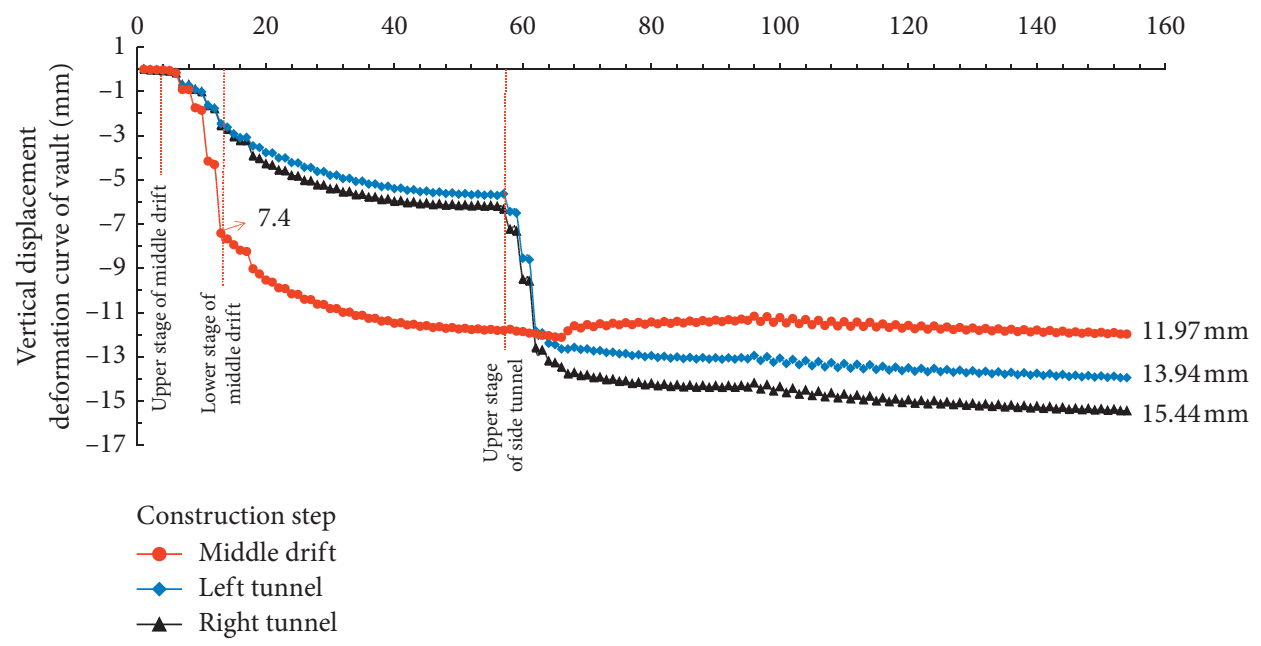

FiguRE 16: Settlement curve of RK0 +300 arch crown.

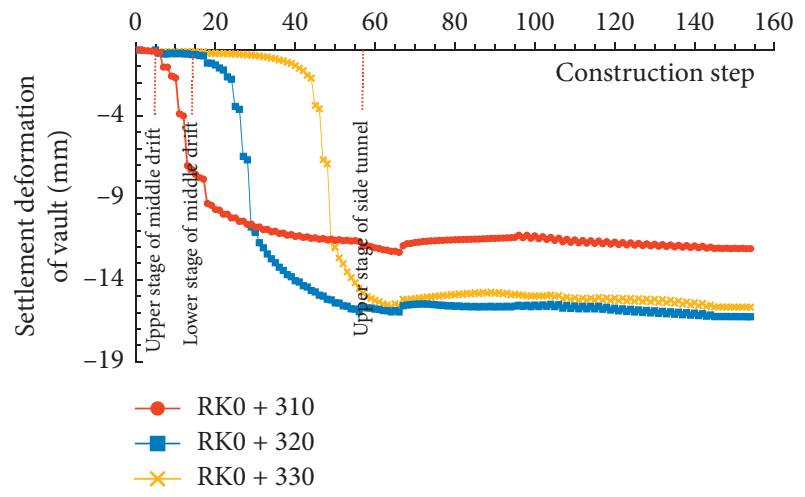

(a)

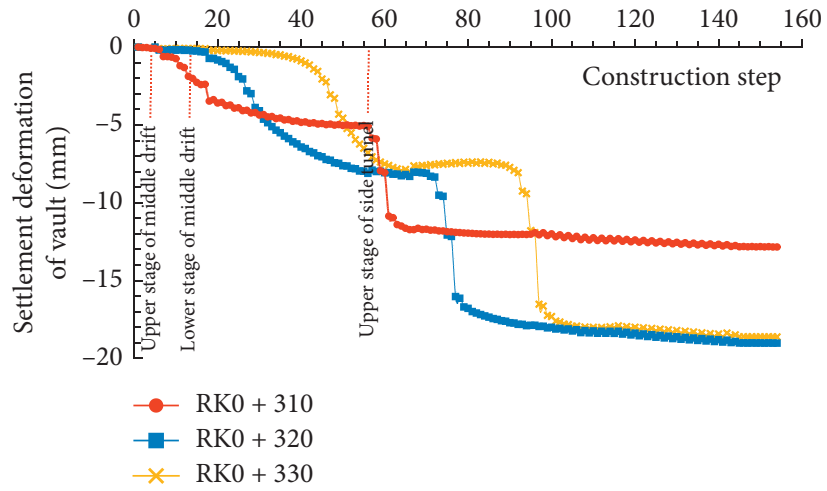

(b)

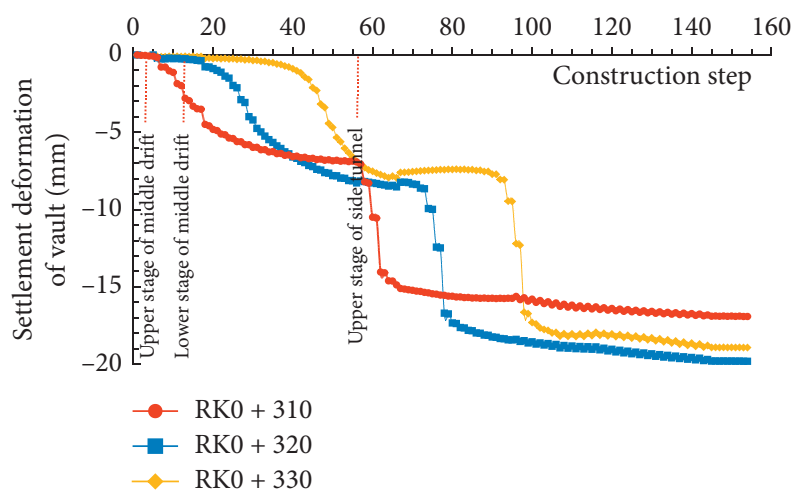

(c)

Figure 17: Settlement curve of vault at different sections. (a) Middle drift. (b) Left tunnel. (c) Right tunnel. 


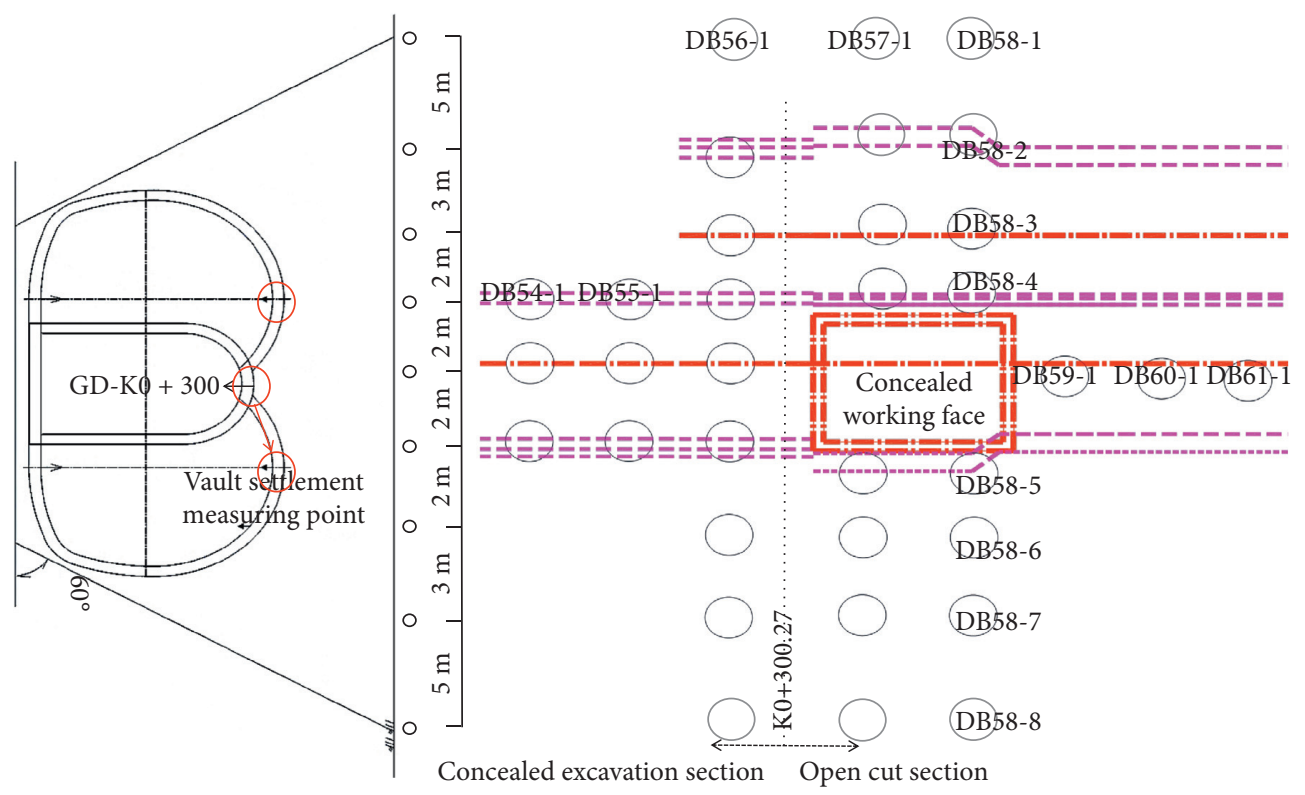

FIGURE 18: Layout of measuring points for land subsidence.

seen that the final settlement of the arch crown of $\mathrm{RK} 0+310$ section is the smallest, indicating that the ingate is properly supported.

\section{Analysis of Field Monitoring Data}

4.1. Monitoring Plan. The layout and distribution of surface settlement monitoring points and vault settlement monitoring points are shown in Figure 18. For the spacing of the surface subsidence measurement section, when the embedding depth $H>2 \mathrm{~B}$, the interval of the surface subsidence measurement section is $20 \sim 50 \mathrm{~m}$. When the buried depth $\mathrm{B}<H<2 \mathrm{~B}$, the interval of the surface subsidence measurement section is taken $10 \sim 20 \mathrm{~m}$; when the buried depth $H<B$, the interval of the surface subsidence measurement section is taken $5 \sim 10 \mathrm{~m}$. The measurement frequency of surface subsidence is the same as the measurement frequency of vault subsidence and headroom level convergence. The interval between the dome subsidence and horizontal convergence measurement sections is $10 \sim 15 \mathrm{~m}$. Surrounding rock changes should be properly encrypted, and 1 to 2 measuring points for vault subsidence should be added to the initial sections of various surrounding rocks.

\subsection{Analysis Monitoring Data}

4.2.1. Ground Settlement. Figure 19 shows the change curve of DB57-4 with monitoring days for the surface monitoring point corresponding to the tunnel construction. At the beginning of monitoring, the ground is excavated $3.5 \mathrm{~m}$ under the shaft. With the continuous excavation of the shaft and the excavation of the middle drift and side tunnel, the ground surface gradually subsides. In the monitoring period of about 50 days, the surface deformation of the transition section tends to be stable, and the maximum settlement value is $11.93 \mathrm{~mm}$. In Figure 20, seven measuring points above the cross passage are selected, and the settlement values of each measuring point in different days are plotted. It can be seen that the maximum value of ground settlement occurs at $10 \mathrm{~m}$ on the left side of the tunnel. Because there is a lock ring at $10 \mathrm{~m}$ to the right of the center line, the settlement value is much smaller than that on the left side, and the settlement value gradually decreases from the tunnel center line toward both sides.

4.2.2. Settlement of the Vault. Figure 21 is the curve of the monitoring point GD-K0+295.5 corresponding to the monitoring days of the construction of the middle drift with the monitoring days. After the construction of the vault support is completed, monitoring of the vaulting begins. With the footage of the middle drift and the excavation of the side tunnels, the vault settlement gradually occurs, which is stable for approximately 80 monitoring days and the value is stable at about $-15.60 \mathrm{~mm}$.

4.3. Comparison of Field Monitoring Results and Numerical Simulation Results. The construction scheme of "middle drift + temporary inverted arch step method" is adopted for the $\mathrm{K} 0+300-+382$ concealed excavation section of the entrance and exit line of the 3A parking lot of Lanzhou Rail Transit Line 2. Compare and analyze the surface settlement and vault settlement in the three-dimensional simulation calculation results with the monitoring data of temporary stability on-site. Table 2 is the comparison table of the surface settlement, vault monitoring data, and simulation data in the changed section of the scheme. The numerical simulation results are slightly smaller than the monitoring data as a whole. On the one hand, when simulating soil materials, the soil is assumed to be an isotropic elastic body of a continuous medium under ideal conditions, but the actual rock mass is a discontinuous anisotropic medium. On the other hand, 


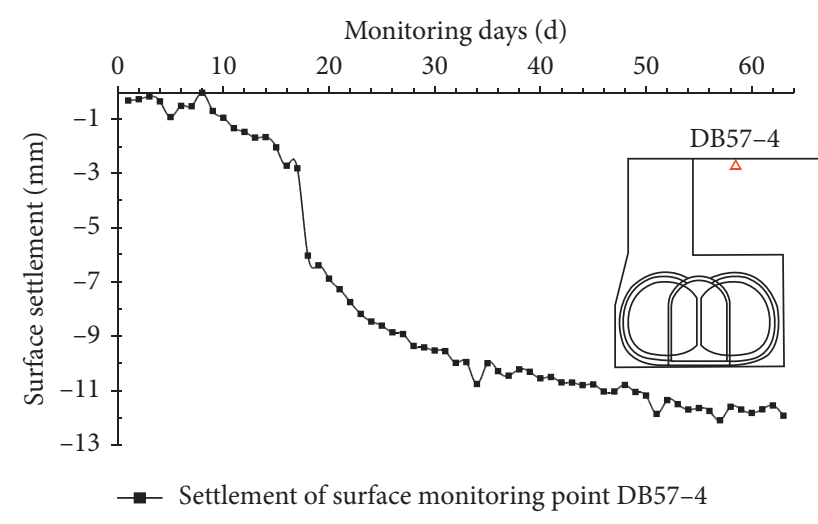

FIGURE 19: Surface monitoring point DB57-4 changes with monitoring days.

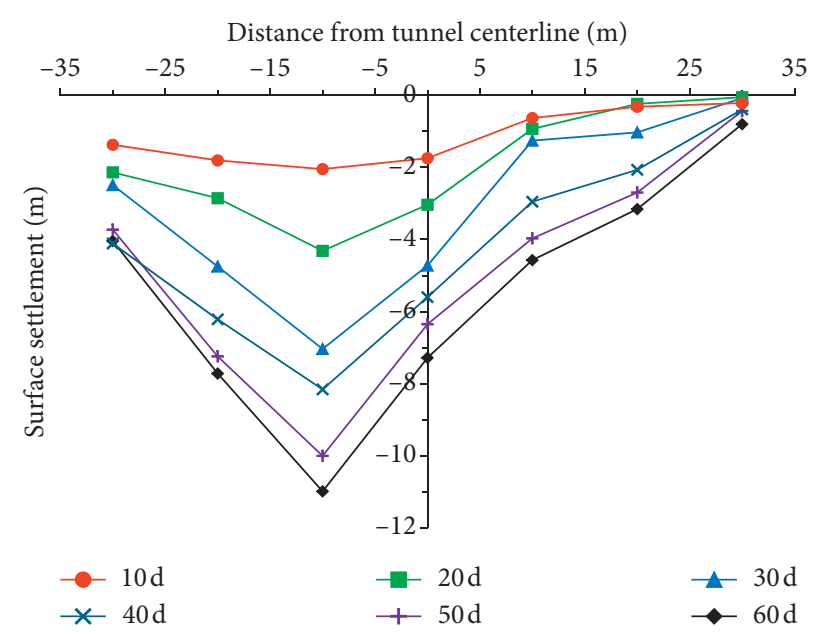

FIgURE 20: Shaft-to-cross passage measurement point varies with monitoring days.

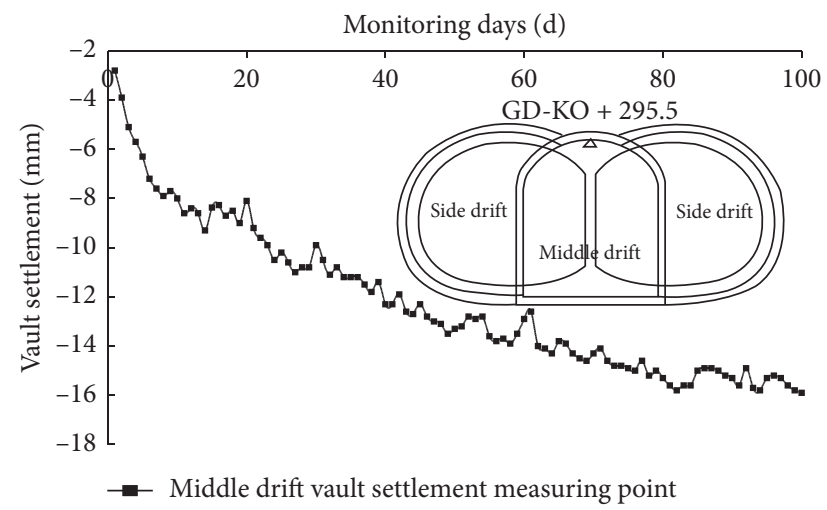

FIGURE 21: The settlement of the vault in the middle guide hole changes with the monitoring days.

because the transverse passage and the surrounding rock of the main tunnel are repeatedly disturbed by construction, the weak structural surfaces and cracks in the surrounding rock are further cracked after being disturbed, resulting in a decrease in the overall strength characteristics of the surrounding rock. The damage inside such surrounding rock cannot be expressed in the finite element simulation. However, through the comparative analysis of the later monitoring results, it can be seen that the difference in the results does not affect the correctness of the law, indicating that the results obtained by the numerical simulation are reliable. It can be seen that the field surface settlement and tunnel settlement are far less than the surface settlement control value of $40 \mathrm{~mm}$, and the vault settlement is less than the control value of $30 \mathrm{~mm}$, which shows that the construction scheme of "middle drift + temporary inverted arch 
TABLE 2: Comparison of field monitoring and simulation data.

\begin{tabular}{lcc}
\hline Measuring point & Surface subsidence $(\mathrm{DB} 57-4)(\mathrm{mm})$ & Settlement of vault in tunnel (GD-K0 + 295.5) \\
\hline Monitoring value & 11.9 & $15.6 \mathrm{~mm}$ \\
Calculated value & 7.1 & $11.97 \mathrm{~mm}$ \\
\hline
\end{tabular}

step method" is safe and feasible, and it is feasible to change the open excavation method to the concealed excavation method. Table 2 shows comparison of on-site monitoring and simulation data.

\section{Conclusions}

Three-dimensional numerical simulation was carried out on the construction process of the open-access section $(\mathrm{K} 0+300 \sim \mathrm{K} 0+382)$ of the parking lot of the $3 \mathrm{~A}$ bid section of the Lanzhou Rail Transit Line 2 to the hidden excavation section. The analysis results show the following:

(1) In the tunnel supporting structure, the stress of the primary lining and the secondary lining meets the requirements of the code. The temporary support of the partition wall in the tunnel has localized tensile stress concentration. Although it is lower than the ultimate tensile strength of the steel, the concrete may be damaged by tension. The spacing between the palm surfaces of the upper and lower steps must be strictly controlled during construction, and the initial support should be increased in time monitoring frequency inside the tunnel.

(2) There is a small range of stress concentration in the vault of the supporting structure of the shaft and the cross passage at the opening of the ingate on the east side. The maximum principal stress of the supporting structure is lower than the ultimate stress of the concrete structure, so the stability of the structure can be maintained during the construction. However, as an important supporting structure in the east of the shaft, it is still necessary to strengthen the initial shaft structure and increase the monitoring frequency of the supporting structure.

(3) In the process of excavation, there is a stress concentration area in the initial support at ingate, and the maximum value of vault settlement after construction also appears at ingate, and the surface settlement and vault settlement change obviously at ingate. Before the construction of ingate, the advance support measures must be taken, and the monitoring frequency of ingate at the east side and the layout density of measuring points should be improved.

(4) According to the distribution of plastic zone caused by the yield of rock mass in tension and compression during the construction, the plastic zone occurs in the arch foot of tunnel structure, the position of arch wall, and the surrounding rock of excavation face, which is easy to cause large deformation in the construction process and even cause the collapse of the soil mass in the face. Therefore, the quality of grouting with small conduit in front of the tunnel must be strictly controlled, and the initial support must be implemented in time.

Compared with the three-dimensional simulation results and monitoring data, there are some differences. On the one hand, when the software simulates the soil material, the soil is considered as a homogeneous and isotropic continuous medium, but in fact, the soil is a heterogeneous and anisotropic discontinuous medium. On the other hand, the construction will bring disturbance to the surrounding rock of the cross passage and the main tunnel, and the weak structural plane and crack in the surrounding rock will further crack after being disturbed, which will reduce the overall strength characteristics of the surrounding rock, while the damage situation in the surrounding rock cannot be expressed in the finite element simulation.

For this project, the scheme change has brought many benefits: (1) the structure of this section is completed in advance with the method of concealed excavation, which guarantees the construction period and improves the use efficiency of the shaft site; (2) the amount of earthwork is reduced by the method of concealed excavation compared with the method of open excavation, which can reduce the breaking and interference to the road surface; (3) the section of open excavation is the deepest section of foundation pit construction, and the scheme change reduces the construction of deep foundation pit safety risk; (4) the north side of the west end of the open excavation is affected by the high-voltage line pole, causing the road to become impassable, so the construction of the open excavation enclosure is canceled to facilitate the traffic dispersion. (5) The construction period is shortened. If the original design remains unchanged, the completion time from the open excavation end to the $1^{\#}$ coving space is December 23, 2018, and the breakthrough time of the secondary lining of the concealed excavation is October 2, 2019. After the change of scheme, the completion time of $\mathrm{K} 0+382$ to $1 \#$ coving space construction is November 13,2018 , and the penetration time of secondary lining of concealed excavation is December 31, 2018. After the change, the open excavation section to the west of 1 \# coving space shall be completed 40 days in advance, and the enclosure can be removed as soon as possible to restore traffic. After the change, the concealed excavation can ensure that the construction period meets the planned construction period, and the original design is 9 months behind the change.

Due to timely changes to the construction plan and proper selection of construction methods, the station has been successfully constructed, ensuring the safe passage of the entire line. The smooth implementation of this project can provide reference for the design and construction of similar projects of urban rail transit. Under the premise of comprehensive consideration of various costs, it is also a good choice to replace the construction method as soon as necessary. 


\section{Data Availability}

The data used to support the findings of this study are included within the article.

\section{Conflicts of Interest}

The authors declare that they have no conflicts of interest regarding the publication of this paper.

\section{Acknowledgments}

The present work was subsidized and supported by the National Natural Science Foundation of China (no. 51578447), the Science and Technology Innovation Team of Shaanxi Innovation Capability Support Plan (no. 2020TD005), Shaanxi Province Housing Urban and Rural Construction Science and Technology Plan Project (no. 2019-K39), the China Postdoctoral Science Foundation (no. 2018M643809XB), and the Natural Science Basic Research Program of Shaanxi (no. 2019JQ-762). The financial supports are gratefully acknowledged by the authors.

\section{References}

[1] S. Fan, Z. Song, Y. Zhang et al., "Case study of the effect of rainfall infiltration on a tunnel underlying the roadbed slope with weak inter-layer," KSCE Journal of Civil Engineering, vol. 24, no. 12, 2020.

[2] H. Dobashi, A. Shiratori, D. Miyama, H. Nagura, and T. Miyawaki, "Design and construction of enlarging shield tunnel sections of large dimensional shield tunnels for the non-open-cut method," Tunnelling and Underground Space Technology, vol. 21, no. 3-4, p. 249, 2006.

[3] J. Soetjahjo, Y. G. Go, and O. H. Bosgra, "Control points of supervision in subway station constructed with open-cut method," Municipal Engineering Technology, vol. 27, no. 9-10, pp. 335-337, 2010.

[4] A. Golshani and M. Rezaeibadashiani, "A numerical study on parameters affecting seismic behavior of cut and cover tunnel," Springer International Publishing, vol. 38, no. 2, 2020.

[5] H. Jinyin and Y. Liu, "Technology for construction of multiarch tunnels with twin large spans and shallow embedment and concealed excavation beneath existing railway," Value Engineering, vol. 31, no. 14, pp. 71-73, 2012.

[6] X. Tian, Z. Song, and Y. Zhang, "Monitoring and reinforcement of landslide induced by tunnel excavation: a case study from Xiamaixi tunnel," Tunnelling and Underground Space Technology, vol. 110, pp. 1-14, 2021.

[7] Y. Guo, Y. Han, X. Zhao et al., "Measured deformation characteristic of open excavation deep foundation pit in suburb railway of wenzhou," Railway Construction Technology, vol. 305, no. 12, pp. 6-8, 2018.

[8] Z. Song, Z. Cao, J. Wang, S. Wei, S. Hu, and Z. Niu, "Optimal analysis of tunnel construction methods through cross passage from subway shaft," Advances in Civil Engineering, vol. 2018, Article ID 5181954, 14 pages, 2018.

[9] J. Wang, "The rapid construction technology of the ingate of return air shaft of zhengzhuang mine," Energy \& Energy Conservation, no. 10, pp. 173-174, 2014.

[10] A. I. Lingjian, "Mine tunneling construction technique for inclined shaft ingate into positive line," Fujian architecture \& Construction, no. 9, pp. 76-79, 2018.
[11] C. Xiao, "Prevention and destroy mechanism of ingate support under conditions of deep mining and high stress," Coal Science \& Technology Magazine, 2011.

[12] Q. Wei, J. Zhang, and J. He, "Design of partial open excavation and hidden excavation scheme of Wenchong Station of Guangzhou Metro Line 5," Urban Rail Transit Research, vol. 16, no. 5, pp. 55-59, 2013.

[13] Y. Jiang, "Feasibility analysis and construction risk control of open excavation and cover excavation of the three-dimensional cross section of Xiangjiang tunnel on Yingpan road," Enterprise Technology Development, vol. 29, no. 23, pp. 48-51, 2010.

[14] L. Jiang, "Analysis of using open digging instead of dark digging to ensure the benefits under pipeline constraints," Shanxi Construction, vol. 37, no. 12, pp. 181-182, 2011.

[15] G. Zhao, "Double-arch tunnel tunnel open excavation section with dark excavation construction technology," Modern Tunnel Technology, vol. 42, no. 1, pp. 77-80, 2005.

[16] W. Yao, "Construction technology of ma tau gate of metro tunnels," Urban Express Rail Transit, vol. 26, no. 4, pp. 100104, 2013.

[17] Q. Jiang, X. Huang, and K. Zhou, "Construction technology and monitoring analysis of horse head gate of subway tunnel under complex conditions," Journal of Rock Mechanics and Engineering, vol. 29, no. S1, pp. 2858-2865, 2010.

[18] C. Xin, Z. Yin, J. Liu et al., "Study on the failure mechanism of Matoumen under non-linear load," Coal Technology, vol. 38, no. 2, pp. 117-119, 2019.

[19] H. Wei, Q. Gao, and W. Yu, "Analysis of excavation support and surrounding rock stability of large-section tunnel," China Mining Industry, no. 10, pp. 80-82 + 85, 2007.

[20] Z. Song, Q. Zhang, K. Zhao et al., "Optimization study on advanced construction of tunnel double-guided tunnel based on on-site monitoring and numerical analysis," Journal of Xi'an University of Architecture and Technology (Natural Science Edition), vol. 50, no. 5, pp. 654-661, 2018.

[21] Z. Song, T. Wang, J. Zhou et al., "Construction optimization and stress characteristics analysis of shallow-buried and biased large-section tunnel," Chinese Journal of Underground Space and Engineering, vol. 13, no. 2, pp. 459-468, 2017.

[22] Z. Xu, Elastic Mechanics, Higher Education Press, Beijing, China, 1982.

[23] Z. Song, X. Tian, L. Qi et al., "Numerical analysis and application of the construction method for the small interval tunnel in the turn line of metro," Ence Progress, vol. 103, no. 3, Article ID 3685042093206, 2020.

[24] X. Tian, Z. Song, G. Zhou, and X. Zhang, "A theoretical calculation method of the unsupported span for the shallow tunnel in the soft stratum," Advances in Civil Engineering, vol. 2020, no. 8, 11 pages, Article ID 7989036, 2020. 